\title{
Lithobius (Monotarsobius) femoratus sp.n., a new centipede species from China (Chilopoda: Lithobiomorpha: Lithobiidae)
}

\author{
Lithobius (Monotarsobius) femoratus sp.n., новый виА губоногих \\ многоножкек из Китая (Chilopoda: Lithobiomorpha: Lithobiidae)
}

\section{Sujian Pei ${ }^{1}$, Huiqin $\mathrm{Ma}^{1,2, *}$, Haipeng Liu ${ }^{1}$, Yanmin $\mathrm{Lu}^{1,2}$, Kuijing Liang ${ }^{1}$ Сучхкань Пеи ${ }^{1}$, Юикинь Ма ${ }^{1,2, *}$, Хаипен $\Lambda{ }^{1}$, Янминь $\Lambda y^{1,2}$,

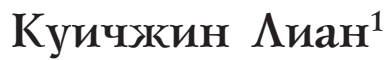

\footnotetext{
${ }^{1}$ Institute of Myriapodology, School of Life Sciences, Hengshui University, Hengshui, Hebei 053000, China.

${ }^{2}$ Hebei Key Laboratory of Wetland Ecology and Conservation, Hengshui, Hebei 053000, China.

* Corresponding author: mhq008@yahoo.com
}

KEY WORDS: Myriapoda, taxonomy, new species, eastern China.

КЛЮЧЕВЫЕ СЛОВА: Myriapoda, таксономия, новый вид, Восточный Китай.

ABSTRACT. A new lithobiid species, Lithobius (Monotarsobius) femoratus sp.n., is described from Hebei Province, China. Morphologically, the new species seems to be extremely close to Lithobius (Monotarsobius) fugax Stuxberg, 1876 from Siberia and Mongolia, but it can easily be distinguished by its two longitudinal grooves on the dorsal side of the femur and one longitudinal groove on the ventral side of male legs 15 , the presence of a $\mathrm{DaC}$ spine on legs 14 and 15 , the dorsal plectrotaxy being 121 in legs 2, 10300 in legs 15, and Tömösváry's organ larger than the adjacent ocelli.

How to cite this paper: Pei Sujian, Ma Huiqin, Liu Haipeng, Lu Yanmin, Liang Kuijing. 2021. Lithobius (Monotarsobius) femoratus sp.n., a new centipede species from China (Chilopoda: Lithobiomorpha: Lithobiidae) // Arthropoda Selecta. Vol.30. No.4. P.497-501. doi: 10.15298/arthsel.30.4.05

РЕЗЮМЕ. Из провинции Хебей (Китая) описана новая костянка: Lithobius (Monotarsobius) femoratus sp.n. Морфологически новый вид, кажется, очень сходен с Lithobius (Monotarsobius) fugax Stuxberg, 1876 из Сибири и Монголии, но легко отличается своими двумя продольными бороздками на спинной стороне бедра и одной продольной бороздкой на брюшной стороне ног 15 самца, наличием шипа $\mathrm{DaC}$ на ногах 14 и 15, дорсальной плектротаксией 121 на ногах 2, 10300 на ногах 15 и более крупным органом Темешвари по сравнению с соседними глазками.

\section{Introduction}

Verhoeff [1905] originally proposed Monotarsobius Verhoeff, 1905 as a subgenus of Lithobius Leach, 1814 in the family Lithobiidae. It presently accommo- dates a group of about 115 species or subspecies mostly known from Eurasia, but some introduced elsewhere. They occur over a wide range of epigeic habitats, from low altitudes to $4200 \mathrm{~m}$ a.s.l., also living in caves. [Zapparoli, Edgecombe, 2011]. Monotarsobius is characterised by the following combination of characters: Forcipular coxosternal teeth $2+2$; porodonts setiform. Tergites without posterior triangular projections. Tarsal articulation of legs 1-13 very faint or indistinct. Secondary sexual modifications sometimes on $\sigma^{7}$ legs 14 and 15. + gonopods with a uni-, bi- or tridentate claw and usually $2+2$ spurs [Zapparoli, Edgecombe, 2011].

The myriapod fauna of China is still poorly known and very little attention has been paid to the study of Lithobiomorpha, with only 100 species or subspecies known from the country. Altogether, 11 species of Monotarsobius have been recorded from China, including only two hitherto reported from the Hebei Province [Takakuwa, 1940; Wang, 1955, 1956, 1957, 1959, 1963; Wang, Mauriès, 1996; Eason, 1997; Ma et al., 2009, 2014; Pei et al., 2011, 2020a, b; Chao et al., 2018, 2020; Qiao et al., 2019]. Below, a new species recently discovered in Hebei Province, China, is described and illustrated.

\section{Materials and methods}

Specimens were collected under leaf litter or stones and preserved in $75 \%$ ethanol. Illustrations and measurements were produced using a ZEISS SteREO Discovery.V20 microscope equipped with an Abbe drawing tube, an ocular micrometre and an Axiocam 512 colour camera. The description is based on specimens fixed in $75 \%$ ethanol. The body length is measured from the anterior margin of the cephalic plate to the posterior end of the postpedal tergite. Type specimens and other material are mostly deposited in the School of Life Sciences, Hengshui University, Heng- 
shui, China (HUSLS), with a few paratypes to be shared with the collection of the Zoological Museum, State University of Moscow (ZMUM), Russia, as indicated below. The terminology of the external anatomy follows Bonato et al. [2010]. Measurements are shown in millimetres $(\mathrm{mm})$. The following abbreviations are used in the text and Table: a anterior, $\mathrm{C}-$ coxa, $\mathrm{F}-$ femur, $\mathrm{m}-$ median, $\mathrm{P}$ - prefemur, $\mathrm{p}$ - posterior; $\mathrm{S}, \mathrm{SS}$ - sternite, sternites, T, TT tergite, tergites, $\mathrm{Ti}$ - tibia, $\mathrm{Tr}$ - trochanter.

\section{Taxonomy}

Family Lithobiidae Newport, 1844

Genus Lithobius Leach, 1814

Subgenus Monotarsobius Chamberlin, 1919

Lithobius (Monotarsobius) femoratus sp.n. Figs 1A-E, 2F-K, Table.

TYPE MATERIAL: HOLOTYPE $\sigma^{\top}$ (Lmon01-1) (Fig. 1A), China, Hebei Province, Shijiazhuang City, Pingshan County, Xiushui Park, 38.093677 S, 114.38752 E, 136 m a.s.1., 28 May 2017, S. Pei, H. Ma leg. PARATYPES: 24 우, $31 \sigma^{\top} \sigma^{\top}$ (Lmon01-1), 2 우, 2 $\sigma^{7} \sigma^{7}$ (ZMUM), same data as holotype.

OTHER MATERIAL: 4 우, $10 \sigma^{\top} \sigma^{\top}$ (Lmon01-2), same place, 3 May 2019, S. Pei, H. Ma leg.

DIAGNOSIS. In accordance with the grouping of species proposed for the subgenus Monotarsobius [Zapparoli, Edgecombe, 2011], the new species differs from other consubgeners in having the antennae composed of 19-21, commonly 20+20 articles, ocelli 6-7, usually 6 on each side, arranged in three irregular rows, with the posterior ocellus the largest, Tömösváry's organ larger than the adjacent ocelli; commonly $2+2$ coxosternal teeth, porodonts lying posterolateral to the lateralmost tooth; coxal pore formula 3-5, arranged in one row; legs 14 and 15 thicker than the anterior pairs in both sexes, with two longitudinal grooves on the dorsal and a central longitudinal groove on the ventral side of the femur of $\sigma^{7}$ legs 15 . + gonopods with $3+3$ moderately small coniform spurs, apical claw of the third article simple, with a larger subtriangular denticle on the ventral side.

ETYMOLOGY. To emphasise that the dorsal side of the femur of $\sigma^{7}$ legs 15 is white in live, translucent in 75\% ethanol.

DESCRIPTION. Holotype $10.9 \mathrm{~mm}$ long, cephalic plate: $1.2 \mathrm{~mm}$ long, $1.2 \mathrm{~mm}$ wide. Body: 9.2-12.5 mm long, cephalic plate 1.16-1.34 mm long, $1.16-1.23 \mathrm{~mm}$ wide.

Coloration: Antennae grey-brown to brown, distal article with yellowish hue; tergites grey-brown with yellowish hue; cephalic plate heavily brown to yellow-brown with blackish hue; pleural region pale grey with purplish hue; sternites pale brown with greyish hue; distal part of forcipules darker yellow-brown, with basal and proximal parts of forcipules and forcipular coxosternite, and SS 14 and 15 yellow-brown with blackish hue; especially, dorsal side of femur of $\sigma^{7}$ legs 15 white in live, but translucent in 75\% ethanol; all legs pale grey, tarsi yellow-brown, tarsus-II darker in all legs.

Antennae with 19-21 articles, commonly 20+20 (Fig. 1A). Antennal article I slightly longer than width at base, remaining articles significantly longer than wide; from article II on, each article gradually shortened, distalmost articles still being significantly, 2.3-3.0 times as long as wide; abundant setae on antennal surface, less so in basal articles, gradually and increasingly setose to approximately article $\mathrm{V}$, then more or less constant.

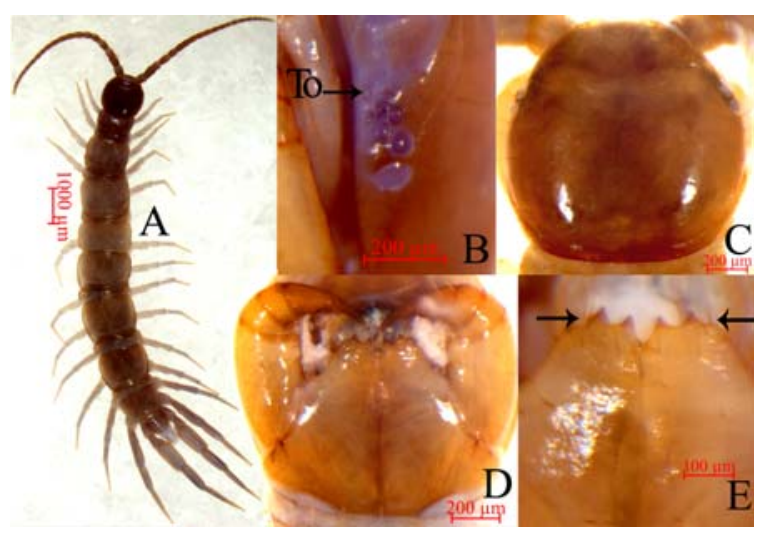

Fig. 1A-E. Lithobius (Monotarsobius) femoratus sp.n., ơ holotype. A - habitus, dorsal view; B - ocelli and Tomosvary's organ (To), lateral view; C - cephalic plate, dorsal view; D cephalic plate, ventral view; E - forcipular coxosternite, ventral view.

Рис. 1А-E. Lithobius (Monotarsobius) femoratus sp.n., голотип $\bigcirc^{\top}$. А - общий вид, сверху; В - глазки и орган Темешвари (То), сбоку; С - головная пластина, сверху; D - головная пластина, снизу; Е - коксостернит ногочелюстей, снизу.

Cephalic plate smooth, convex, equal to or slightly longer than wide; tiny setae emerging from pores scattered very sparsely over the whole surface; frontal marginal ridge with a shallow anteromedian furrow; short to long setae very sparsely scattered along marginal ridge of cephalic plate; lateral marginal ridge discontinuous, posterior margin continuous, straight, slightly wider than lateral marginal ridge (Fig. 1C).

Ocelli six to seven, commonly six oval ocelli on each side, from small to large, arranged in three irregular rows, posterior ocellus the largest. Ventral ocelli smaller than dorsal ones, domed, translucent and usually dark (Fig. 1B).

Tömösváry's organ located close to ocelli at anterolateral margin of cephalic plate, surrounding sclerotised area always narrow, slightly larger than adjoining ocelli (Fig. 1B, To).

Coxosternite subtrapezoidal (Fig. 1D), anterior margin narrow, lateral margins slightly longer than medial margins; median diastema moderately deep, U-shaped; anterior margin with $2+2$ acute triangular teeth; porodonts feebly thicker, posterolateral, separated from lateral tooth, lying posteriolaterally to lateralmost tooth, with a marked bulge at base (Fig. 1D, E); long setae scattered on ventral side of coxosternite, longer setae near dental margin.

All tergites smooth, without wrinkles, dorsum slightly convex; tiny setae emerging from pores scattered sparsely over entire surface; T1 narrower posterolaterally than anterolaterally, generally inverted trapezoidal; cephalic plate and $\mathrm{T} 1$ obviously narrower than $\mathrm{T} 3$, cephalic plate slightly wider than $\mathrm{T} 1$. Lateral marginal ridges of all tergites continuous. Posterior margin of TT 1, 3 and 5 continuous, posterior margin of TT 10, 12 and 14 discontinuous. Posterior marginal ridges of TT 1,3 and 5 feebly concave, posterior marginal ridges of TT 8, 10, 12 and 14 moderately concave. Posterior angles of tergites rounded, without triangular projections. Short to long miniscule setae scattered sparsely over surface.

Sternites: Posterior side of sternites narrower than anterior one, generally inverted trapezoidal, smooth; setae emerging from very sparsely scattered pores on surface and at 


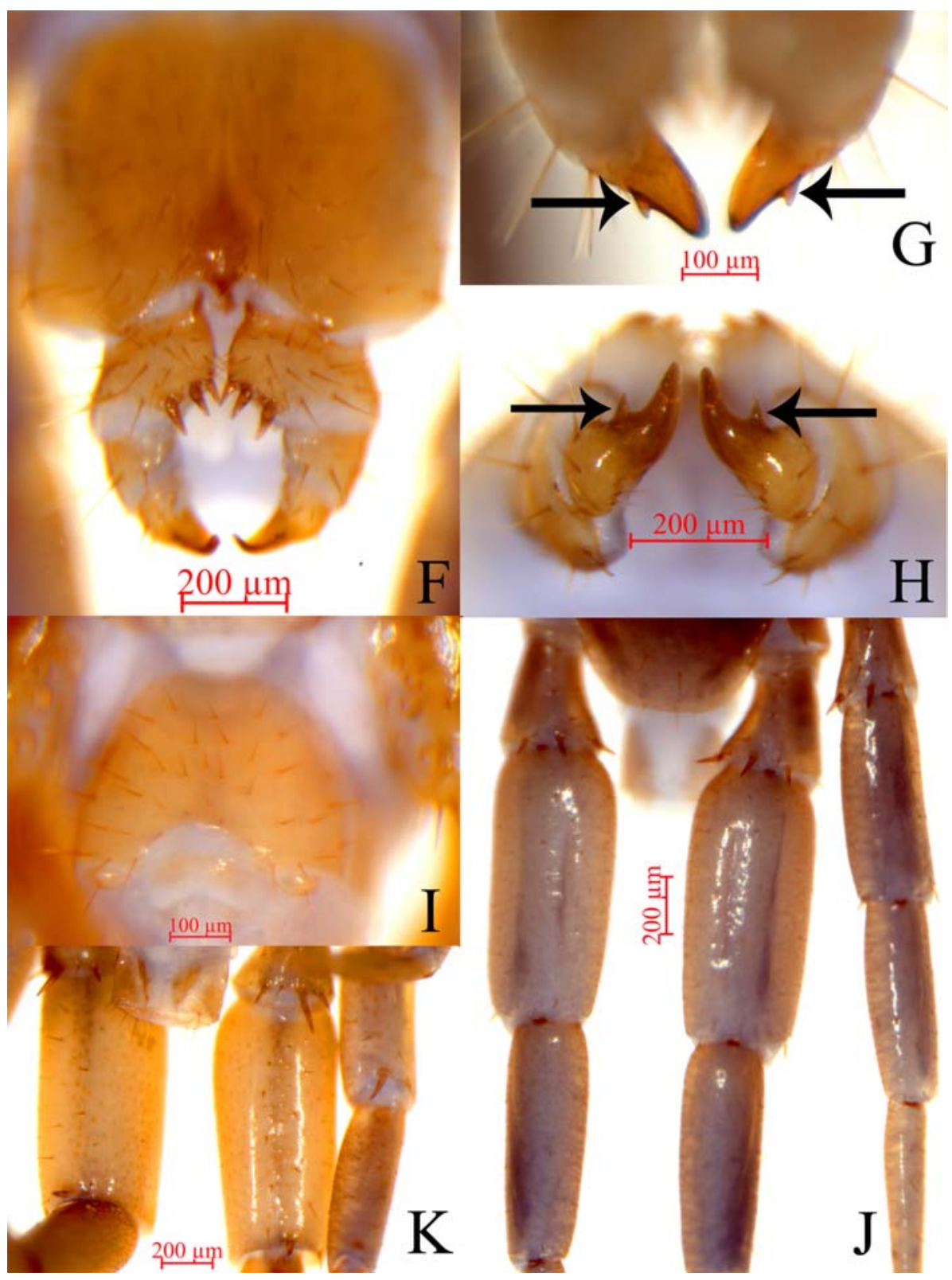

Fig. 2F-K. Lithobius (Monotarsobius) femoratus sp.n., , p paratype (F-H), $\mathrm{O}^{7}$ holotype (I-K). F - posterior segments and gonopods, ventral view; G, H - apical claw of gonopods, ventral and dorsal views, respectively; H-I - posterior segments and gonopods, ventral view $\mathrm{J}, \mathrm{K}-$ femur of legs 15 , dorsal and ventral views, respectively.

Рис. 2F-K. Lithobius (Monotarsobius) femoratus sp.n., паратип + (F-H), голотип О (I-K). F - задние сегменты и гоноподы, снизу; G, H - вершинный коготь гоноподов, соответственно снизу и сверху; H-I — задние сегменты и гоноподы, снизу; J, K бедро ног 15 , соответственно сверху и снизу.

lateral margin. Middle part of each sternite with a very shallow depression. One pair of approximately symmetrically arranged long setae in middle part of anterior portion, and 2-3 long setae in anterior and posterior parts of each sternite.

Legs: Relatively robust, tarsi ill-defined on all legs, tarsal articulations on dorsal side indistinct, being visible only as a shallow ventral suture; well-defined on legs 14 and 15 . From short to long setae sparsely scattered over surface of coxa, trochanter, prefemur, femur, and tibia of all legs, more setae on tarsal surface; setae on dorsal and ventral surfaces slightly longer; some notably thickened setae arranged in one row on ventral surface of tarsi 1-13, no setae arranged in one row on ventral surface of tarsi 14 and 15. All legs with moderately long and curved claws; legs $1-13$ with anterior and posterior accessory spurs, anterior accessory spurs moderately long and slender, forming a moderately small angle to claw; posterior accessory spurs slightly more robust, forming a comparatively large angle to claw, only posterior accessory spurs present in legs 14 and 15 . Legs 14 and 15 thicker than anterior pairs in both sexes, $\sigma^{7}$ legs 15 thicker and stronger than 9 ones. Femur $2.2-2.4$ or $1.8-2.0$ times longer than width in + and $\sigma^{7}$, respectively. Tarsus-II, 
Table. Leg plectrotaxy of Lithobius (Monotarsobius) femoratus sp.n. Таблица. Плектротаксия ног у Lithobius (Monotarsobius) femoratus sp.n.

\begin{tabular}{|c|c|c|c|c|c|c|c|c|c|c|}
\hline \multirow{2}{*}{ legs } & \multicolumn{5}{|c|}{ ventral } & \multicolumn{5}{c|}{ dorsal } \\
\cline { 2 - 11 } & $\mathrm{C}$ & $\mathrm{Tr}$ & $\mathrm{P}$ & $\mathrm{F}$ & $\mathrm{Ti}$ & $\mathrm{C}$ & $\mathrm{Tr}$ & $\mathrm{P}$ & $\mathrm{F}$ & $\mathrm{Ti}$ \\
\hline 1 & & & $\mathrm{p}$ & $\mathrm{am}$ & $\mathrm{m}$ & & & $\mathrm{p}$ & $\mathrm{a}$ & $\mathrm{a}$ \\
\hline 2 & & & $\mathrm{p}$ & $\mathrm{am}$ & $\mathrm{m}$ & & & $\mathrm{p}$ & $\mathrm{ap}$ & $\mathrm{a}$ \\
\hline 3 & & & $\mathrm{p}$ & $\mathrm{amp}$ & $\mathrm{am}$ & & & (a)p & ap & $\mathrm{ap}$ \\
\hline 4 & & & $\mathrm{mp}$ & $\mathrm{am}(\mathrm{p})$ & $\mathrm{am}$ & & & $\mathrm{ap}$ & $\mathrm{ap}$ & $\mathrm{ap}$ \\
\hline $5-10$ & & & $\mathrm{mp}$ & $\mathrm{amp}$ & $\mathrm{am}$ & & & $\mathrm{ap}$ & $\mathrm{ap}$ & $\mathrm{ap}$ \\
\hline $11-12$ & & & $\mathrm{mp}$ & $\mathrm{amp}$ & $\mathrm{am}$ & & & $\mathrm{amp}$ & $\mathrm{ap}$ & $\mathrm{ap}$ \\
\hline 13 & & & $\mathrm{mp}$ & $\mathrm{amp}$ & $\mathrm{am}$ & & & $\mathrm{amp}$ & $\mathrm{p}$ & $\mathrm{p}$ \\
\hline 14 & & $\mathrm{~m}$ & $\mathrm{amp}$ & $\mathrm{am}$ & $\mathrm{m}$ & $\mathrm{a}$ & & $\mathrm{amp}$ & $\mathrm{p}$ & \\
\hline 15 & & $\mathrm{~m}$ & $\mathrm{amp}$ & $\mathrm{am}$ & & $\mathrm{a}$ & & $\mathrm{amp}$ & & \\
\hline
\end{tabular}

NB: Letters in brackets indicate variable spines.

3.6-4.9 times longer than width; tarsus-II, $71.7 \%-94.7 \%$ or $69.7-87.2 \%$ length of tarsus-I of legs 15 in $\%$ and $\sigma^{7}$, respectively; tarsus-II, 4.0-4.5 times longer than width. Leg plectrotaxy as in Table.

Coxal pores: Round, $3-5$ in a row, 3-4-4-4 in smaller 오, 4-5-5-5 in larger $09,3-4-4-4(3)$ in $0^{7} \sigma^{7}$; commonly round, coxal pore field set inside a relatively shallow groove, coxal pore-field fringe with a slight prominence and moderately long setae sparsely scattered over surface.

: S 15 anterior margin broader than posterior one, posterior angles generally rounded, posterior marginal ridges straight. Moderately long setae sparsely scattered on S 15 surface. Surface of lateral sternal margin of genital segment well-chitinised, posterior margin of genital sternite deeply concave between condyles of gonopods, except for a small, median, rhomboid bulge. Short to long setae very sparsely scattered over ventral surface of genital segment, slightly more setae in posterior part, especially at posterior edge. Gonopods: first article fairly broad, bearing 20-22 moderately long setae arranged in three irregular rows; with $3+3$ small coniform spurs, inner spur slightly smaller than outer one (Fig. 2F); second article with 3-5 long setae in ventral part, arranged in two irregular rows; third article with 3-5 long setae in ventral part, arranged in two irregular rows, with a simple apical claw with a larger subtriangular denticle in ventral part (Fig. 2G, H).

$\mathrm{O}^{7}: \mathrm{S} 15$ posterior margin narrower than anterior one, straight posteromedially, generally inverted trapezoidal, covered with sparse long setae; sternite of genital segment evidently smaller than in $\odot$, usually sclerotised; posterior margin deeply concave between gonopods, without medial bulge. Short to long setae equably scattered over ventral surface of genital segment. Gonopods short, each appearing as a small ball-like bulge with a long seta, slightly sclerotised apically (Fig. 2I). With two longitudinal grooves on dorsal side of femur of legs 15, of which outer groove 2 times as long as inner one, with a clear black line therein; outer groove wide and shallow, inner one narrow and deeper; with a narrow, central, longitudinal groove extending to terminal end of ventral side of femur 15 (Fig. 2J, K).
HABITAT. Under the leaf litter of a mixed pine and poplar forest.

COMMENTS. Morphologically, the new specie seems to be extremely close to Lithobius (Monotarsobius) fugax Stuxberg, 1876 [Stuxberg, 1876; Loksa, 1965; Zalesskaja, 1978] from Siberia and Mongolia, with which it shares the antennae with 19-21 articles, and 6-7 ocelli on each side, the posterior ocellus being the largest, $2+2$ prosternal teeth, and the coxal pore formula as $3-5$, 9 gonopods with $3+3$ moderately small coniform spurs, apical claw of the third article simple, with a larger subtriangular denticle on the ventral side. However, they can easily be distinguished by the following characters: the new species has two longitudinal grooves on the dorsal side and one longitudinal groove on the ventral side of the femur of $\sigma^{7}$ legs $15, v s$. no other special features except that the dorsal side is slightly flat in L. (M.) fugax; DaC spine on legs 14 and 15, vs. DaC spine on legs 13,14 and 15 in L. (M.) fugax; the dorsal plectrotaxy is 121 in legs 2, 10300 in legs 15,vs. 222 in legs 2, 10310 in legs 15 in L. (M.) fugax; Tömösváry's organ larger than the adjacent ocelli. vs. smaller than the adjacent ocelli in $L$. (M.) fugax.

Acknowledgements. We thank Prime Proofreaders and Dr. Sergei Golovatch (Moscow, Russia) for their linguistic help. We are particularly indebted to Dr. Gyulli Farzalieva (Perm, Russia) for her very useful suggestions and valuable literature she provided as a reviewer. This study was supported by the project of Hebei Provincial Key Laboratory of Wetland Ecology and Conservation (No.hklz201908), the National Natural Science Foundation of China (NSFC grant No. 31572239), the Natural Science Foundation of Hebei Province (Grant No. C2018111019), and the Key Discipline of Zoology of Hengshui University. We are grateful to Dr. Gregory D. Edgecombe (London, UK), Dr. Pavel Stoev (Sofia, Bulgaria) and Dr. Marzio Zapparoli (Viterbo, Italy), for their hospitality and valuable assistance during our research. We thank Dr. Rowland M. Shelley, North Carolina, USA, and Dr. His-Te Shih, Taichung, China, for providing us with invaluable literature. 


\section{References}

Bonato L., Edgecombe G.D., Lewis J.G.E., Minelli A., Pereira L.A., Shelley R.M., Zapparoli M. 2010. A common terminology for the external anatomy of centipedes (Chilopoda) // ZooKeys. Vol.69. P.17-51.

Chao J.L., Lee K.S., Chang H.W. 2018. Lithobius (Monotarsobius) meifengensis, a new species of centipede from high altitude forest in central Taiwan (Chilopoda, Lithobiomorpha, Lithobiidae) // ZooKeys. No.741. P.181-192.

Chao J.L., Lee K.S., Chang H.W. 2020. Two new species of centipedes, Lithobius keelungensis sp. nov. and Lithobius (Monotarsobius) qingquanensis sp. nov., from Taiwan (Chilopoda, Lithobiomorpha, Lithobiidae) // Opuscula Zoologica, Budapest. Vol.51. Suppl.2. P.47-56.

Eason E.H. 1997. On some Lithobiomorpha from the mountains of Kizghizia and Kazakhstan (Chilopoda) // Arthropoda Selecta. Vol.6. No.1-2. P.117-121.

Loksa I. 1965. Zoologische Ergebnisse der Forschungen von Dr. Z. Kaszab in der Mongolei. 21. Chilopoda // Opuscula Zoologica, Budapest. Vol.5. P.199-215.

Ma H.Q., Pei S.J., Hou X.J., Zhu T.G., Wu D.Y., Gai Y.H. 2014 An annotated checklist of Lithobiomorpha of China // Zootaxa. Vol.3847. No.3. P.333-358.

Ma H.Q., Pei S.J., Wu D.Y., Gai Y.H. 2012. Lithobius (Monotarsobius) monoforaminis sp. n., a new species of lithobiid centipede from central China (Chilopoda, Lithobiomorpha, Lithobiidae) // ZooKeys. Vol.193. P.79-87.

Ma H.Q., Pei S.J., Zhu M.S., Zhang G.C., Liu L.L. 2009. A new species of Lithobius (Monotarsobius) Verhoeff, 1905 (Lithobiomorpha: Lithobiidae) from China // Entomological News. Vol.120. No.3. P.313-318.

Pei S.J., Lu Y.M., Iiu H.P., Hou X.J., Ma H.Q. 2020a. Lithobius (Monotarsobius) brachyspinipes sp. n., a new species of centipede from China (Lithobiomorpha, Lithobiidae) // Transactions of the American Entomological Society. Vol.146. No.2. P.341-353.

Pei S.J., Ma H.Q., Iiu H.P., Lu Y.M., Hou X.J. 2020b. Lithobius (Monotarsobius) varioporus, a new species from eastern China (Lithobiomorpha, Lithobiidae) // ZooKeys. Vol.931. P.35-48.

Pei S.J., Ma H.Q., Shi B.J., Wu D.Y., Zhou W.J. 2011. A new species of Lithobius (Monotarsobius) Verhoeff, 1905 (Lithobiomorpha, Lithobiidae) from China // ZooKeys. Vol.82. P.5966.
Qiao P.H., Qin W., Ma H.Q., Zhang T.Z., Su J.P., Lin G.H. 2019. Two new species of lithobiid centipedes and the first record of Lamyctes africanus Porath (Chilopoda: Lithobiomorpha) in China // Journal of Natural History. Vol.53. Nos 15-16. P.897921.

Stuxberg A. 1876. Myriopoder från Sibirien och Waigatsch ön samlade under Nordenskiöldska expeditionen 1875 // Öfversigt af Kongliga Vetenskaps-Akademiens Förhandlingar. Bd.33. H.2. S.11-38.

Takakuwa Y. 1940. Class Chilopoda, Epimorpha, Lithobiomorpha // Fauna Nipponica. Vol.9. Fasc.8. No.3. Tokyo: Sanseido Book Store. 104 pp.

Verhoeff K.W. 1905. Über die Entwickelungsstufen der Steinläufer Lithobiiden und Beiträge zur Kenntnis der Chilopoden // Zoologische Jahrbücher, Abteilung für Systematik. Supplement 8 . S.195-298.

Wang Y.H.M. 1955. Serica 1a: Records of myriapods on Formosa with description of new species // Quarterly Journal of the Taiwan Museum. Vol.8. No.1. P.13-16.

Wang Y.H.M. 1956. Serica 1e: Records of myriapods on Formosa with description of new species (2) // Quarterly Journal of the Taiwan Museum. Vol.9. No.2. P.155-159.

Wang Y.H.M. 1957. Serica 1f: Records of myriapods on Taiwan Islands (3) - Pescadore Islets, Kao-Yung, Pingtung, Changhua and Taipei // Quarterly Journal of the Taiwan Museum. Vol.10. No.1. P.23-29.

Wang Y.H.M. 1959. Serica 1j: On Chilopoda from Taiwan with a new lithobiid // Quarterly Journal of the Taiwan Museum. Vol.12. Nos 3-4. P.195-199.

Wang Y.H.M. 1963. Serica 1q: Millipedes and centipedes of Quemoy, Fukien Province and Taiwan Island, Botel Tobago (Lan Yu), Taiwan Province and of Singapore // Quarterly Journal of the Taiwan Museum. Vol.16. Nos 1-2. P.89-96.

Wang D.Q., Mauriès J.P. 1996. Review and perspective of study on myriapodology of China // Acta Myriapodologica, Mémoires du Muséum national d'Histoire naturelle. Vol.169. P.81-99.

Zalesskaja N.T. 1978. [Identification book of the lithobiomorph centipedes of the USSR (Chilopoda Lithobiomorpha)]. Moscow: Nauka Publ. 212 pp. [In Russian]

Zapparoli M., Edgecombe G.D. 2011. Lithobiomorpha // Minelli A (ed.). Treatise on Zoology - Anatomy, Taxonomy, Biology The Myriapoda, Vol.1. Leiden - Boston: Brill. P.371-389.

Responsible editor S.I. Golovatch 